\title{
Xanthophyllum fragrans C.T. White Leaf Extracts Inhibit the Growth of Pseudomonas aeruginosa
}

\author{
Lindiwe Mpala', Getmore Chikowe ${ }^{1}$, lan Edwin Cock ${ }^{1,2, *}$ \\ ISchool of Environment and Science, Griffith University, 170 Kessels Rd, Nathan, Brisbane, Queensland, AUSTRALIA \\ 2Environmental Futures Research Institute, Griffith University, 170 Kessels Rd, Nathan, Brisbane, Queensland, AUSTRALIA.
}

\begin{abstract}
Introduction: Xanthophyllum fragrans C.T. White is a rainforest tree that is native to north-eastern regions of Australia. $X$. fragrans leaf extracts were examined for the ability to inhibit the growth of Pseudomonas aeruginosa. Methods: The antimicrobial activity of a methanolic $X$. fragrans leaf extracts were investigated by disc diffusion and growth time course assays against $P$. aeruginosa. The growth inhibitory activity was further quantified by MIC determination. Toxicity was determined using the Artemia franciscana nauplii bioassay. Results: The methanolic $X$. fragrans leaf extract was a potent inhibitor of $P$. aeruginosa growth (MICs of 430 and $1687 \mu \mathrm{g} / \mathrm{mL}$ against the reference and clinical strains respectively). The aqueous $X$. fragrans leaf extract was also a moderate inhibitor of $P$. aeruginosa growth (MICs approximately 1000 and $2500 \mu \mathrm{g} / \mathrm{mL}$ against the reference and clinical bacterial strains respectively). The antibacterial activities of the methanolic $X$. fragrans leaf extracts were further investigated using growth time course assays that showed significant growth inhibition in cultures of $P$. aeruginosa within $1 \mathrm{~h}$ of exposure. All extracts were determined
\end{abstract}

to be non-toxic in the Artemia franciscana nauplii bioassay, indicating their safety for use in preventing diseases caused by these pathogens. Conclusion: The lack of toxicity of the $X$. fragrans leaf extracts and their growth inhibitory bioactivity against $P$. aeruginosa indicates their potential in the development of new therapies targeting this bacterium.

Key words: Polygalaceae, Fragant boxwood, Australian plant, Traditional medicine, Antibacterial, Cystic fibrosis, Multiple sclerosis.

\section{Correspondence:}

Dr. Ian Edwin Cock ${ }^{1,2}$

'School of Environment and Science, Griffith University, 170 Kessels Rd, Nathan, Brisbane, Queensland 4111, AUSTRALIA

2Environmental Futures Research Institute, Griffith University, 170 Kessels Rd, Nathan, Brisbane, Queensland 4111, AUSTRALIA.

Phone no: +61 737357637

E-mail: I.Cock@griffith.edu.au

DOI: $10.5530 /$ pc.2019.3.22

\section{INTRODUCTION}

Plants produce a wide variety of secondary compounds that provide them characteristic pigment, odour and flavour characteristics and may also give them antimicrobial properties. Traditional plant derived medicines have been used in most parts of the world for a variety of therapeutic purposes, including fighting microbial disease. Indeed, the ability of plant extracts to block the growth of pathogenic bacteria has become a focus of substantial recent study. ${ }^{1,2}$ Much of the research into traditional medicinal plant use has focused on Asian, ${ }^{3}$ African ${ }^{4}$ and South American ${ }^{5}$ plants. The first Australians had well-developed medicinal systems and understood the therapeutic properties of a wide variety of Australian plants and how to use them effectively. ${ }^{6}$ Despite this, relatively few studies have rigorously examined the antibacterial activity of Australian native plants, although there has recently been a substantial increase in interest in this field.

The development of antibiotic agents to treat Pseudomonas aeruginosa infections is particularly important as this pathogen may extensively colonise infected tissue and can aggregate to produce enduring biofilms that are particularly difficult to eradicate. $P$. aeruginosa is an opportunistic, nosocomial pathogen which most frequently infects the airways, urinary tract, burns and wounds, particularly in immunocompromised people. ${ }^{7}$ The bacterium is a frequent coloniser of medical devices (e.g. catheters) and is readily spread via contaminated equipment. Cystic fibrosis patients are particularly predisposed to P. aeruginosa infections of the lungs and if left untreated, they may be fatal. ${ }^{8,9}$ Furthermore, $P$. aeruginosa is recognised as a bacterial trigger of multiple sclerosis in genetrically susceptible individuals. ${ }^{10,11}$ Of further concern, $P$. aeruginosa is resistant to most frontline antibiotic therapies due to its multiple efflux pumps which are encoded by mexAB, mexXY etc. resistance genes (Poole 2004). The bacterium cell envelope also has low permeability to most antibiotics, further limiting their intracellular concentrations. This has vastly limited the number of effective antibiotics for use against this bacterium. Further exacerbating the problem, many P. aeruginosa strains have also accumulated genes for the production of antibiotic degrading/ inactivating enzymes such as extended-spectrum $\beta$-lactamases, AmpC cephalosporinases, carbapenemases, aminoglycoside-modifying enzymes etc. Combined, these resistance mechanisms make $P$. aeruginosa infections particularly difficult to treat and new, effective antibiotics are urgently required.

Xanthophyllum fragrans C.T. White (family Polygalaceae; commonly known as fragrant boxwood) is a small to medium sized tree which is native to rainforest regions of north eastern Australia. The tree has large, pale, lanceolate to ovate leaves, with entire margins that grow up to $20 \mathrm{~cm}$ long by $7 \mathrm{~cm}$ wide (Figure 1a). White flowers with purple/mauve streaks (Figure 1a) develop into elliptical shaped fruit $(\sim 9 \mathrm{x} 4 \mathrm{~cm})$. Whilst there is a lack of studies reporting the ethnobotanical uses, bioactivity and phytochemistry of $X$. fragrans leaves, several studies have examined the ethnobotany, bioactivities and phytochemistry of other Xanthophyllum spp. Xanthophyllum excelsum root decoctions are used by the Lundayeh people of Sabah, Malaysia to treat gastritis. ${ }^{12}$ Extracts prepared using young branches of Xanthophyllum neglectum are used in Borneo to treat cold sweats and trembling. ${ }^{13}$ A further study reported good antiPlasmodium falciparum activity $\left(\mathrm{IC}_{50}<2 \mu \mathrm{g} / \mathrm{mL}\right.$ ) for the Philippines species Xanthophyllum flavescens Roxb. against two $P$. falciparum strains, including a chloroquine resistant strain. ${ }^{14}$ Interestingly, that study also reported the $X$. flavescens extracts to be non-toxic in both Artemia nauplii and human cell line cytotoxicity assays. Whilst the phytochemistry of Xanthophyllum spp. is relatively unreported, studies have reported that some species contain relatively levels of tannins, ${ }^{13}$ including gallic acid (Figure 1b) and protocatechuic acid (Figure 1c). Despite the earlier studies into the use and therapeutic properties of other Xanthophyllum spp., we were unable to find similar reports into the therapeutic properties of $X$. fragrans. Our study was undertaken to screen of $X$. fragrans leaf extracts for growth inhibitory properties against the important human bacterial pathogen, $P$. aeruginosa. 


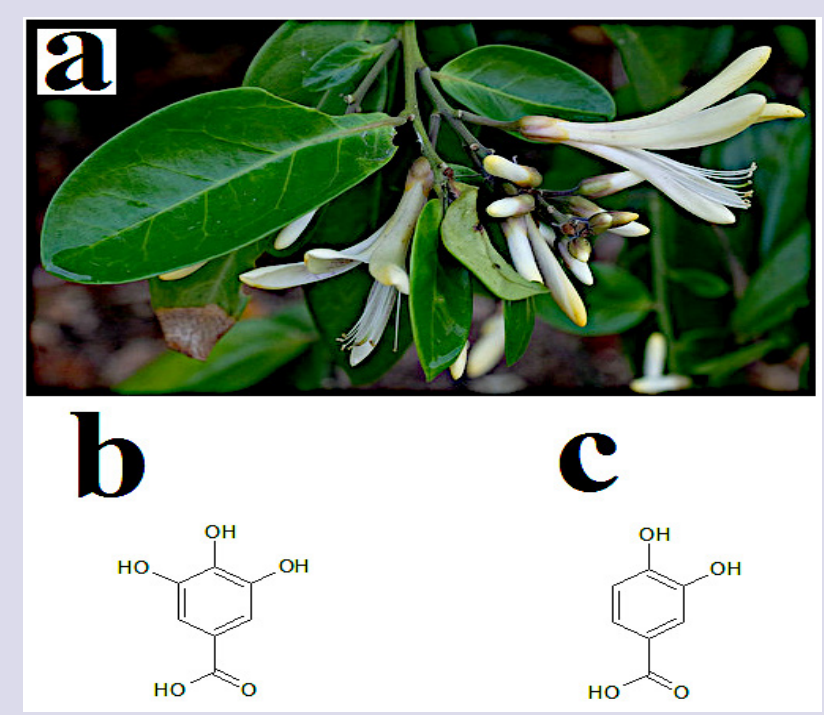

Figure 1: X. fragrans (a) leaves and flowers, as well as the phytochemical compounds (b) gallic acid and (c) protocatechuic acid.

\section{MATERIALS AND METHODS}

\section{Plant collection and extraction}

Xanthophyllum fragrans C.T. White leaves were obtained from Philip Cameron, senior botanical officer, Mt Cootha Botanical Gardens, Brisbane, Australia. The leaf samples were dried in a Sunbeam food dehydrator and stored at $-30^{\circ} \mathrm{C}$. Prior to use, the dried leaves were freshly ground to a coarse powder and $1 \mathrm{~g}$ quantities were weighed into separate tubes. A volume of $50 \mathrm{~mL}$ methanol (Ajax Fine Chemicals, Australia) or deionised water was added and the plant material was extracted for $24 \mathrm{~h}$ at $4^{\circ} \mathrm{C}$ with gentle shaking. The extracts were filtered through filter paper (Whatman No. 54) under vacuum, followed by drying by rotary evaporation. The resultant pellet was dissolved in $10 \mathrm{~mL}$ sterile deionised water (containing 1\% DMSO). The extracts were passed through $0.22 \mu \mathrm{m}$ filter (Sarstedt) and stored at $4^{\circ} \mathrm{C}$ until use.

\section{Qualitative phytochemical studies}

Phytochemical analysis of the $X$. fragrans leaf extracts for the presence of saponins, phenolic compounds, flavonoids, phytosteroids, triterpenoids, cardiac glycosides, anthraquinones, tannins and alkaloids was conducted by standard assays. ${ }^{15-17}$

\section{Antibacterial screening Test microorganisms}

All media was supplied by Oxoid Ltd., Australia. The reference strain of Pseudomonas aeruginosa (ATCC39324) was purchased from American Tissue Culture Collection, USA. The clinically isolated strain of P. aeruginosa was obtained from the School of Natural Sciences teaching laboratory, Griffith University. All stock cultures were subcultured and maintained in nutrient broth at $4^{\circ} \mathrm{C}$.

\section{Evaluation of antimicrobial activity}

Antimicrobial activity of the $X$. fragrans extracts was determined using a modified disc diffusion assay. ${ }^{18-20}$ Briefly, $100 \mu \mathrm{L}$ of each bacterial culture was grown in $10 \mathrm{~mL}$ of fresh nutrient broth until they reached a count of $\sim 10^{8}$ cells $/ \mathrm{mL}$. A volume of $100 \mu \mathrm{L}$ of the bacterial suspension was spread onto nutrient agar plates and the extracts were tested for antibacterial activity using $5 \mathrm{~mm}$ sterilised filter paper discs. Discs were infused with $10 \mu \mathrm{L}$ of the plant extract, allowed to dry and placed onto the inoculated plates. The plates were allowed to stand at $4^{\circ} \mathrm{C}$ for $2 \mathrm{~h}$ before incubation at $30^{\circ} \mathrm{C}$ for $24 \mathrm{~h}$. The diameters of the zones of inhibition (ZOIs) were measured to the closest whole millimetre. Each assay was performed three times in triplicate $(n=9)$. Mean values $( \pm$ SEM) are reported in this study. Standard discs of ampicillin $(10 \mu \mathrm{g})$ and chloramphenicol $(10 \mu \mathrm{g})$ were obtained from Oxoid, Australia and were used as positive controls to compare antibacterial activity. Filter discs infused with $10 \mu \mathrm{L}$ of distilled water were used as a negative control.

\section{Minimum inhibitory concentration (MIC) determination}

The minimum inhibitory concentration (MIC) of each extract was determined as previously described. ${ }^{21,22}$ Briefly, the methanolic $X$. fragrans leaf extract was diluted in deionised water and tested across a range of concentrations. Discs were infused with $10 \mu \mathrm{L}$ of the test dilutions, allowed to dry and placed onto the inoculated plates. The assay was completed as outlined above and graphs of the zone of inhibition versus concentration were plotted for each extract. Linear regression was used to determine the MIC values of each extract.

\section{Bacterial growth time course assay}

Bacterial growth time course studies were performed as previously described. ${ }^{23}$ Briefly, $3 \mathrm{~mL}$ of $P$. aeruginosa (ATCC39324) in nutrient broth was added to $27 \mathrm{~mL}$ nutrient broth containing $3 \mathrm{~mL}$ of $10 \mathrm{mg} / \mathrm{mL}$ of each individual extract to give a final concentration of $1000 \mu \mathrm{g} / \mathrm{mL}$ in the assay. The tubes were incubated at $30^{\circ} \mathrm{C}$ with gentle shaking. The optical density was measured hourly at $550 \mathrm{~nm}$ for a $6 \mathrm{~h}$ incubation period. Control tubes were incubated under the same conditions but without the extract. All assays were performed in triplicate.

\section{Toxicity screening}

\section{Reference toxin for toxicity screening}

Potassium dichromate $\left(\mathrm{K}_{2} \mathrm{Cr}_{2} \mathrm{O}_{7}\right)$ (AR grade, Chem-Supply, Australia) was prepared as a $4 \mathrm{mg} / \mathrm{mL}$ solution in distilled water and was serially diluted in artificial seawater for use in the Artemia franciscana nauplii bioassay.

\section{Artemia franciscana nauplii toxicity screening}

Toxicity was tested using an adapted Artemia franciscana nauplii lethality assay. ${ }^{24-26}$ Briefly, $400 \mu \mathrm{L}$ of seawater containing approximately 44 (mean 44.3, $n=125$, SD 11.6) A. franciscana nauplii were added to wells of a 48 well plate and immediately used for bioassay. A volume of $400 \mu \mathrm{L}$ of diluted plant extracts or the reference toxin were transferred to the wells and incubated at $25 \pm 1^{\circ} \mathrm{C}$ under artificial light (1000 Lux). A $400 \mu \mathrm{L}$ seawater negative control was run in triplicate for each plate. All treatments were performed in at least triplicate. The wells were checked at regular intervals and the number of dead counted. The nauplii were considered dead if no movement of the appendages was detected within $10 \mathrm{sec}$. After $24 \mathrm{~h}$, all nauplii were sacrificed and counted to determine the total $\%$ mortality per well. The $\mathrm{LC}_{50}$ with $95 \%$ confidence limits for each treatment was determined using probit analysis.

\section{Statistical analysis}

Data are expressed as the mean \pm SEM of at least three independent experiments. One-way ANOVA was used to calculate statistical significance between control and treated groups with a $P$ value $<0.01$ considered to be statistically significant. 
Table 1: The mass of dried extracted material, the concentration after resuspension in deionised water and qualitative phytochemical screenings of the $X$. fragrans leaf extracts.

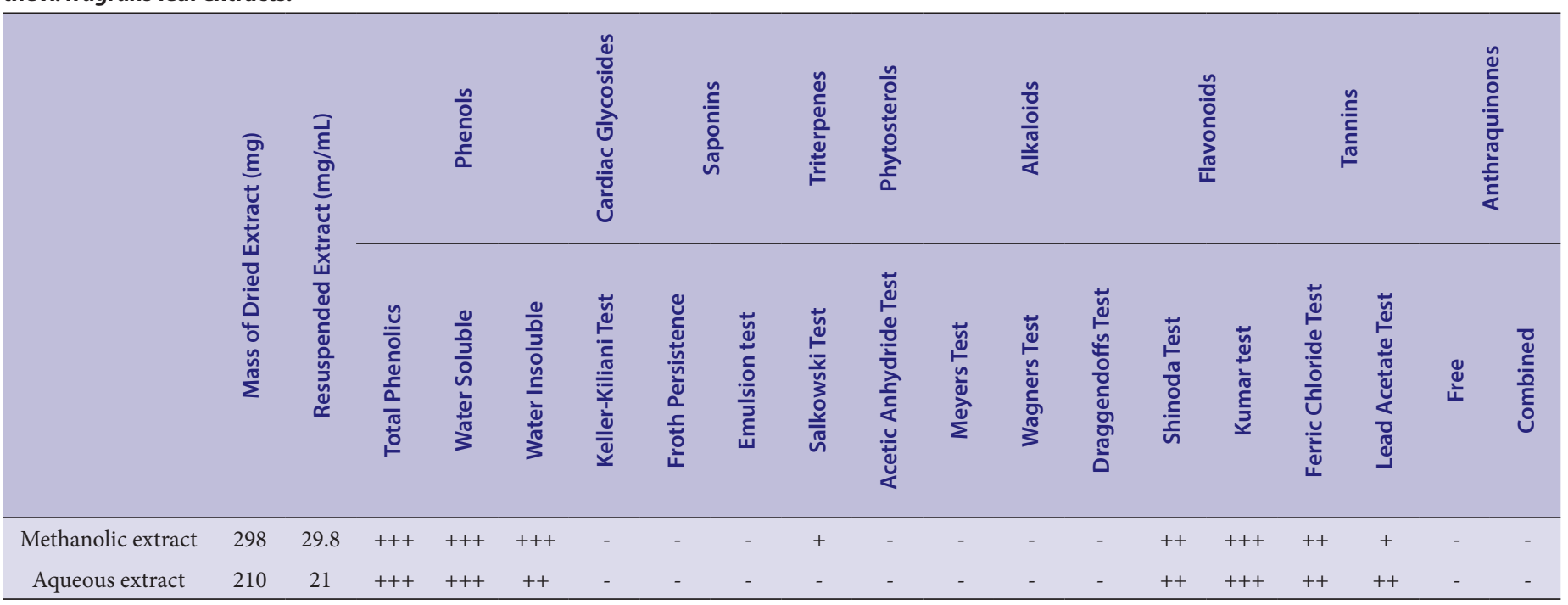

+++ indicates a large response; ++ indicates a moderate response; + indicates a minor response; - indicates no response in the assay.

\section{RESULTS}

\section{Liquid extraction yields and qualitative phytochemical screening}

Extraction of $1 \mathrm{~g}$ of dried and powdered $X$. fragrans leaves with methanol or water yielded 298 and $210 \mathrm{mg}$ of dried extract respectively (Table 1). The extracts were resuspended in $10 \mathrm{~mL}$ of deionised water (containing $1 \%$ DMSO), resulting in extract concentrations of 29.8 and $21.0 \mathrm{mg} / \mathrm{mL}$ respectively. Qualitative phytochemical studies showed that both extracts contained high levels of phenolics and flavonoids, as well as moderate levels of tannins. All other phytochemical classes were completely absent, or below the detection thresholds for these assays.

\section{Antimicrobial activity}

To determine the growth inhibitory activity of the $X$. fragrans leaf extracts against the two $P$. aeruginosa strains, aliquots $(10 \mu \mathrm{L})$ of each extract were screened in the disc diffusion assay. The $X$. fragrans leaf extract inhibited the growth of both the reference and clinical isolate strains of $P$. aeurginosa (Figure 2). The reference strain was substantially more sensitive to the $X$. fragrans extracts and to the control antibiotics than was the clinically isolated strain. The methanolic extracts was a particularly good inhibitor of the reference strain, with a zone of inhibition of $10.3 \pm 0.6 \mathrm{~mm}$. The potency of this extract compared well with that of the positive control antibiotics ampicillin and chloramphenicol (ZOIs of $10.2 \pm 0.6 \mathrm{~mm}$ and $13.3 \pm 0.3 \mathrm{~mm}$ respectively). The inhibition of this extract is particularly noteworthy as each of the control antibiotics were tested at high doses $(10 \mu \mathrm{g} / \mathrm{disc})$. The methanolic extract also was a good inhibitor of the growth of the clinical strain, albeit with substantially smaller zones of inhibition measured $(9.2 \pm 0.3 \mathrm{~mm})$. The aqueous extract produced smaller ZOIs against both bacterial strains, although the measured ZOIs $(\geq 8.5 \mathrm{~mm})$ still indicate good inhibitory activity.

The antimicrobial efficacy was further quantified by determining the MIC value (Table 2). The methanolic $X$. fragrans leaf extract was a particularly potent inhibitor of the growth of the reference $P$. aeruginosa strain, with an MIC value of $430 \mu \mathrm{g} / \mathrm{mL}$ ( $\sim 4 \mu \mathrm{g}$ infused into the disc). This extract was also a strong inhibitor of the clinical isolate $P$. aeruginosa strain (MIC $975 \mu \mathrm{g} / \mathrm{mL}$ ). As $P$. aeruginosa can trigger multiple sclerosis in genetically susceptible people, ${ }^{27-30}$ this extract may be useful for

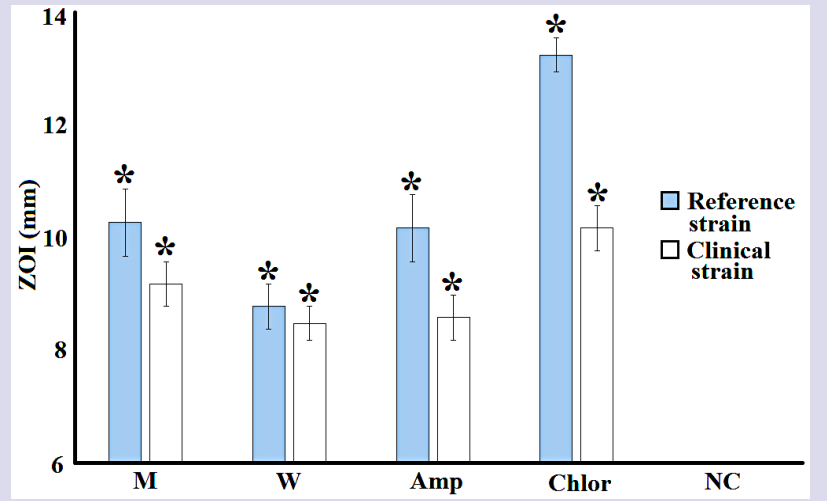

Figure 2: Growth inhibitory activity of $X$. fragrans leaf extracts and reference antibiotics against reference and clinical strains of $P$. aeruginosa measured as zones of inhibition $(\mathrm{mm}) \pm \mathrm{SEM}$. Blue bars represent the growth inhibition activity of the $X$. fragrans against the reference bacterial strain; clear bars represent the growth inhibition activity of the $X$. fragrans against the clinically isolated bacterial strain. $M=$ methanolic extract; $W=$ aqueous extract; $A m p=$ ampicillin

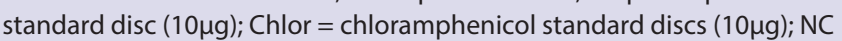
$=$ negative (untreated) control. All assays were completed three times, each with internal triplicates $(n=9)$ and the results are expressed as mean zones of inhibition $(\mathrm{mm}) \pm \mathrm{SEM}$. * indicates results that are significantly different to the untreated control results $(P<0.01)$.

preventing this disease (and other diseases caused by this bacterium). This extract may also be particularly beneficial in individuals with cystic fibrosis, to limit pulmonary infections, thereby increasing their quality of life and life expectancy. Generally, substantially higher MIC values were determined for the aqueous extract (1500-2500 $\mu \mathrm{g} / \mathrm{mL}$; equivalent to $\sim 15-25 \mu \mathrm{g}$ infused into the disc). Whilst substantially less potent than the methanolic extract, these MIC values are still indicative of moderate inhibitory activity. Therefore, the aqueous extract may still be useful in the development of new anti-P. aeruginosa therapies. 

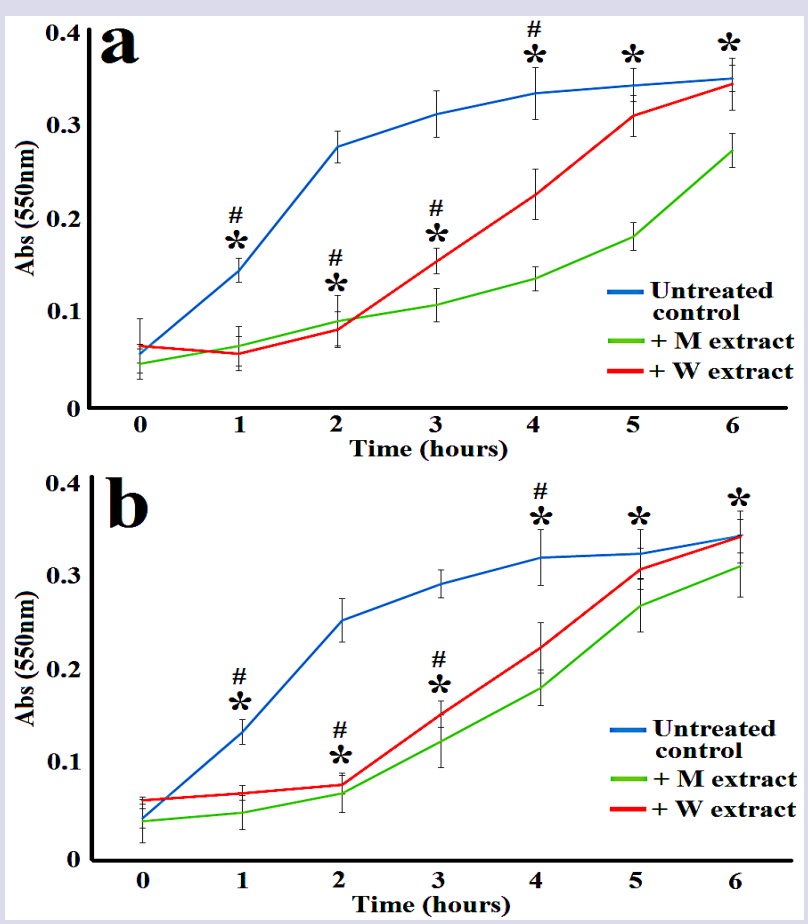

Figure 3: Bacterial growth curves for the $X$. fragrans extract against the $P$. aeruginosa (a) reference strain and (b) clinical isolate. All bioassays were performed three times in triplicate $(n=9)$ and are expressed as mean \pm SEM. ${ }^{*}=$ results that are significantly different between the methanol extract treated bacteria and the untreated control growth $(P<0.01)$; \# $=$ results that are significantly different between the aqueous extract treated bacteria and the untreated control growth $(P<0.01)$.

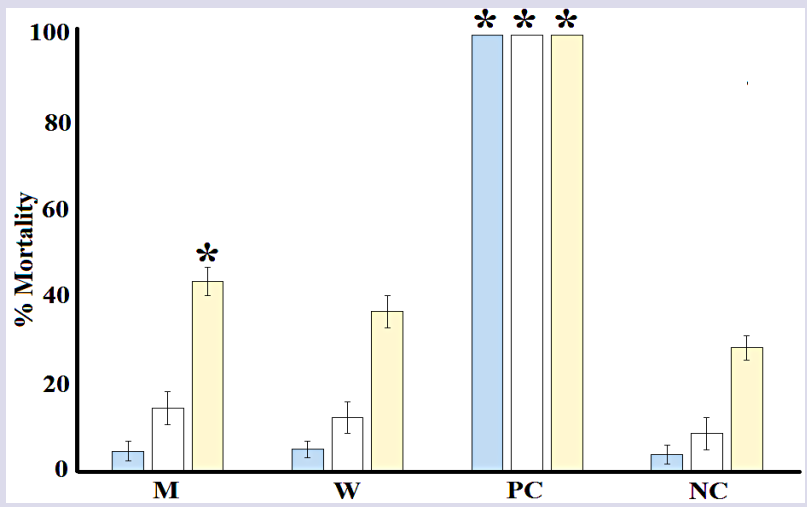

Figure 4: The lethality of the $X$. fragrans leaf extracts, potassium dichromate control $(1000 \mu \mathrm{g} / \mathrm{mL}$ ) and seawater (negative control). Blue bars represent the $\%$ mortality following $24 \mathrm{~h}$ exposure to the extract; clear bars represent the $\%$ mortality following $48 \mathrm{~h}$ exposure to the extract; yellow bars represent the $\%$ mortality following $72 \mathrm{~h}$ exposure to the extract; $\mathrm{M}=$ methanolic extract; $\mathrm{W}=$ aqueous extract; $\mathrm{PC}=$ potassium dichromate control; $\mathrm{NC}$ = seawater (negative) control. All bioassays were performed three times in triplicate $(n=9)$ and are expressed as mean \pm SEM. ${ }^{*}$ indicates results that are significantly different to the untreated (seawater) control at the equivalent exposure time $(P<0.01)$
Table 2: Minimum inhibitory concentrations $(\mu \mathrm{g} / \mathrm{mL})$ of the $X$. fragrans leaf extracts against the $P$. aeruginosa strains and $L C_{50}$ values $(\mu \mathrm{g} / \mathrm{mL})$ against Artemia nauplii.

\begin{tabular}{cccc}
\hline & & \multicolumn{2}{c}{ MIC or LC $_{50}(\mu \mathrm{g} / \mathrm{mL})$} \\
\hline Bacteria/toxicity & Exposure time $(\mathrm{h})$ & $\mathrm{M}$ & $\mathrm{W}$ \\
\hline P. aeruginosa (ATTC39324) & 24 & 430 & 975 \\
P. aeruginosa (clinical strain) & 24 & 1687 & 2446 \\
& 24 & $\mathrm{CND}$ & $\mathrm{CND}$ \\
$\mathrm{LC}_{50}(\mu \mathrm{g} / \mathrm{mL})$ & 48 & $\mathrm{CND}$ & $\mathrm{CND}$ \\
& 72 & $\mathrm{CND}$ & $\mathrm{CND}$ \\
\hline
\end{tabular}

Numbers indicate the mean MIC or $\mathrm{LC}_{50}$ values of three independent experiments in triplicate $(n=9)$. CND indicates that an $\mathrm{LC}_{50}$ could not be determined as the mortality did not exceed $50 \%$ at any concentration tested.

\section{Bacterial growth time course assay}

The antibacterial activity of the $X$. fragrans leaf extracts was further investigated against the reference (Figure $3 a$ ) and clinical strains (Figure $3 b$ ) of the bacterium by bacterial growth time course assays in the presence and absence of the methanolic and aqueous $X$. fragrans extracts. The starting concentration of the extracts used in these assays was $1000 \mu \mathrm{g} / \mathrm{mL}$. The $X$. fragrans methanolic and aqueous extracts significantly inhibited the growth of both $P$. aeruginosa strains within $1 \mathrm{~h}$ of exposure, indicating a rapid antimicrobial action. The absorbance of both $P$. aeruginosa strain cultures in the presence of the aqueous extract (and thus the bacterial growth) had returned to similar levels to that of the untreated control by the end of the $6 \mathrm{~h}$ incubation period. This may indicate that the aqueous $X$. fragrans extract has bacteriostatic effects against $P$. aeruginosa. Similarly, the growth of the clinical $P$. aeruginosa isolate had returned to similar levels as the untreated control by the end of the $6 \mathrm{~h}$ incubation (Figure $3 \mathrm{~b}$ ). In contrast, the $\mathrm{A}_{550}$ of the reference $P$. aeruginosa culture in the presence of the methanolic extract was substantially lower than the untreated control following $6 \mathrm{~h}$ exposure (Figure $3 \mathrm{a}$ ). However, the absorbance was increasing towards the control value at $6 \mathrm{~h}$, indicating that this extract was still have bacteriostatic effects against the reference $P$. aeruginosa strain at the concentration tested.

\section{Quantification of toxicity}

The toxicity of the $X$. fragrans extracts was initially tested undiluted in the Artemia franciscana nauplii bioassay (Figure 4). The mortality in the presence of both extracts was not significantly different to that of the untreated control at $24 \mathrm{~h}$ and thus both extracts were non-toxic. Extracts with $24 \mathrm{~h} \mathrm{LC}_{50}$ values $>1000 \mu \mathrm{g} / \mathrm{mL}$ have previously been defined as non-toxic. ${ }^{26}$ In contrast, the potassium dichromate positive control induced substantial mortality within $4 \mathrm{~h}$ (results not shown), with $100 \%$ mortality induction seen by $24 \mathrm{~h}$. By $48 \mathrm{~h}$, the mortality induction had also increased in the presence of both $X$. fragrans extracts and this increased further by $72 \mathrm{~h}$ exposure. However, the \% mortality was still $<50 \%$ at all times tested. Thus, both $X$. fragrans extracts were deemed to be non-toxic.

\section{DISCUSSION}

Plant derived remedies are increasingly sought after in the treatment of a myriad of diseases and disorders, due both to their perception of greater safety than synthetic drugs and the failure of some current drug regimens to effectively treat disease. New therapeutics are required particularly urgently for the treatment of $P$. aeruginosa infections due to the serious nature of some of the illnesses caused by this bacterium, as well as the resistance of this bacterium to most current antibiotics. $P$. aeruginosa infections are a major cause of lung infections in people 
with cystic fibrosis. Cystic fibrosis sufferers have mutations in the gene encoding CF-transmembrane conductance regulator protein, ${ }^{7}$ resulting in ineffective electrolyte secretion function and viscous mucus. As mucociliary clearance is a major mechanism of lung defense against bacterial infections, individuals with cystic fibrosis are ineffective at clearing these bacteria, resulting in chronic lung infections (most frequently $P$. aeruginosa infections). If not effectively treated, these infections may be fatal. Indeed, $P$. aeruginosa lung infections are the major cause of morbidity and mortality in people with cystic fibrosis. ${ }^{8,9}$ P. aeruginosa (and Acinetobacter spp.) can also trigger multiple sclerosis in genetically susceptible people. ${ }^{27-30}$ Thus, limiting Acinetobacter spp. and $P$. aeruginosa infections in the GI and/or respiratory tracts before they interact with the immune system may prevent the downstream inflammatory phase of the disease.

Of further concern, $P$. aeruginosa has multiple efflux pumps encoded by mexAB, mexXY etc resistance genes, ${ }^{31}$ making it resistant to most antibiotics in clinical usage. Furthermore, the $P$. aeruginosa cell envelope has low permeability to many clinically used antibiotics, further limiting their efficacy. Some $P$. aeruginosa strains have also accumulated genes for the production of antibiotic degrading/inactivating enzymes such as extended-spectrum $\beta$-lactamases, AmpC cephalosporinases, carbapenemases, aminoglycoside-modifying enzymes etc. Combined, these resistance mechanisms make $P$. aeruginosa infections particularly difficult to treat and new, effective antibiotics are urgently required. Probing traditional medicines and natural plant resources offers an alternate means of fighting bacterial diseases and may provide future therapies to treat $P$. aeruginosa infections.

Our study reports on the growth inhibitory properties of a methanolic and aqueous $X$. fragrans leaf extracts against two strains of $P$. aeruginosa and on their toxicity. The methanolic extract was a particularly potent inhibitor of $P$. aeruginosa growth (MICs of 430 and $1687 \mu \mathrm{g} / \mathrm{mL}$ against the reference and clinical strains respectively). The aqueous $X$. fragrans leaf extract was also a moderate inhibitor of $P$. aeruginosa growth (MICs approximately 1000 and $2500 \mu \mathrm{g} / \mathrm{mL}$ against the reference and clinical bacterial strains). Therefore, these extracts may be useful in treating lung infections in cystic fibrosis sufferers. Furthermore, as $P$. aeruginosa may trigger multiple sclerosis in genetically susceptible individuals, ${ }^{27-30}$ these extracts may also be useful in the prevention and treatment of that autoimmune disease.

Whilst a detailed investigation of the phytochemistry of the $X$. fragrans leaf extracts was beyond the scope of our study, qualitative screening studies were used to determine the classes of compounds present. Notably, the extract contained relatively high levels of total phenolics, flavonoids and tannins. It is likely that these and other phytochemical classes may contribute to the growth inhibitory properties of the $X$. fragrans extracts. Many studies have reported potent antibacterial activities for a wide variety of compounds of these classes. ${ }^{32}$ Tannins have potent, broad spectrum growth inhibitory activity against a variety of bacterial species. ${ }^{33}$ Gallotannins have particularly well reported inhibitory properties. ${ }^{34}$ They function via multiple mechanisms including interacting with both cell surface protein $s^{35,36}$ and through interactions with intracellular enzymes ${ }^{32,33}$ Ellagitatannins also interact with cellular proteins and induce disruptions in bacterial cell walls. ${ }^{34,35}$ Similarly, multiple studies have reported potent antibacterial activity for a variety of flavonoids against a broad panel of pathogenic bacteria. ${ }^{32,33}$ Indeed, that report highlighted the growth inhibition of a methicillin resistant Staphylococcus aureus (MRSA) by luteolin. It is therefore likely that the tannin and flavonoid components of the $X$. fragrans leaf extracts may contribute to the bacterial growth inhibitory activity reported in our study. However, it is likely that other phytochemical components of these extracts may also contribute to the efficacy of these extracts. Further phytochemical evaluation studies and bioactivity driven isolation of active components is required to further evaluate the mechanism of bacterial growth inhibition.

The findings reported here also demonstrate that the $X$. fragrans leaf extracts were non-toxic towards Artemia franciscana nauplii, with $\mathrm{LC}_{50}$ values substantially $>1000 \mu \mathrm{g} / \mathrm{mL}$. Extracts with $\mathrm{LC}_{50}$ values $>1000 \mu \mathrm{g} / \mathrm{mL}$ towards Artemia nauplii are defined as being non-toxic. ${ }^{26}$ Whilst our preliminary toxicity studies indicate that these extracts may be safe for therapeutic use, studies using human cell lines are required to further evaluate the safety of these extracts. Furthermore, whilst these studies have demonstrated the potential of the $X$. fragrans leaf extracts in the development of future antibiotic chemotherapeutics to treat $P$. aeruginosa infections such as those associated with cystic fibrosis and the induction of multiple sclerosis in genetically susceptible people (as well as other diseases caused by $P$. aeruginosa infections), more work is required to isolate the inhibitory components and determine the mechanism of inhibition. Whilst these studies have demonstrated the potential of the methanolic $X$. fragrans leaf extract in the development of future antibiotic chemotherapeutics, more work is required to isolate the inhibitory components and determine the mechanism of inhibition.

\section{CONCLUSION}

The results of this study demonstrate the potential of the $X$. fragrans leaf extracts as inhibitors of the growth of $X$. fragrans. Furthermore, their lack of toxicity indicates that they are safe therapeutically. Further studies aimed at the purification and identification of bioactive components are required to examine the mechanisms of action of these agents.

\section{ACKNOWLEDGEMENT}

The authors are grateful to Philip Cameron for identifying and providing the plant material used in this study. We are also grateful to Michelle Mendell and Jane Gifkins for the gift of the clinical isolate bacterial strain. Financial support for this work was provided by the Environmental Futures Research Institute and the School of Natural Sciences, Griffith University, Australia.

\section{CONFLICT OF INTEREST}

The authors report no conflicts of interest.

\section{ABBREVIATIONS}

DMSO: Dimethyl sulfoxide; $\mathbf{L C}_{50}$ : The concentration required to achieve 50 \% mortality; MIC: Minimum inhibitory concentration; ZOI: Zone of inhibition.

\section{REFERENCES}

1. Bhavnani SM, Ballow $\mathrm{CH}$. New agents for Gram-positive bacteria. Current Opinion in Microbiology. 2000;3(5):528-34

2. Chiariandy $\mathrm{CM}$, Seaforth $\mathrm{CE}$, Phelps $\mathrm{RH}$, et al. Screening of medicinal plants from Trinidad and Tobago for antimicrobial and insecticidal properties. Journal of Ethnopharmacology. 1999;64(3):265-70.

3. Patwardhan B, Warude D, Pushpangadan $\mathrm{P}$, et al. Ayurveda and traditional Chinese medicine: a comparative overview. Evidence-based Complimentary and Alternative Medicine. 2005;2(4):465-73

4. Hostettmann K, Marston A, Ndjoko K, et al. The potential of African plants as a source of drugs. Current Organic Chemistry. 2000;4(10):973-1010.

5. Paz EA, Cerdeiras MP, Fernandez J, et al. Screening of Uruguayan medicinal plants for antimicrobial activity. Journal of Ethnopharmacology. 1995;45(1):67-70.

6. Cock IE. Medicinal and aromatic plants-Australia. In Ethnopharmacology, Encyclopedia of Life Support Systems. 2011.

7. Oliver $\mathrm{A}$, Canton $\mathrm{R}$, Campo $\mathrm{P}$, et al. Higfh frequency of hypermutatable Pseudomonas aeruginosa in cystic fibrosis lung infection. Science. 2000;288(5469):1251-3

8. Goldman MJ, Anderson GM, Stolzenberg ED, et al. Human $\beta$-defensin-1 is a salt-sensitive antibiotic in lung that is inactivated in cystic fibrosis. Cell. 
1997;88(4):553-60

9. Smith JJ, Travis SM, Greenberg EP, et al. Cystic fibrosis airway epithelia fail to kill bacteria because of abnormal airway surface fluid. Cell. 1996;85(2):229-36.

10. Cock IE, Cheesman MJ. The early stages of multiple sclerosis: new targets for the development of combinational drug therapies. In Neurological Disorders and Imaging Physics. 2019;1.

11. Courtney R, Sirdaarta J, Matthews B, et al. Tannin components and inhibitory activity of Kakadu plum leaf extracts against microbial triggers of autoimmune inflammatory diseases. Pharmacognosy Journal. 2015;7(1):18-31. DOI: 10.5530/ pj.2015.7.2

12. Kulip J, Majawat G, Kulik J. Medicinal and other useful plants of the Lundayeh community of Sipitang, Sabah, Malaysia. Journal of Tropical Forest Science. 2000;12(4):810-6.

13. Ma'ruf A, Atmoko N, Atmoko T. Medicinal oroperties of Bornean Orangutan food plants in Gunung Beratus protected forest, East Kalimantan, Indonesia. The First International Conference of Indonesian Forestry Researchers. 2011.

14. Horgen FD, Edrada RA, Los RD, et al. Biological screening of rain forest plot trees from Palawan Island (Philippines). Phytomedicine. 2001;8(1):71-81.

15. Boyer $\mathrm{H}$, Cock IE. Evaluation of the potential of Macademia integriflora extracts as antibacterial food agents. Pharmacognosy Communications. 2013;3(3):53-62. DOI: $10.5530 / p c .2013 .3 .10$

16. Hart $C$, Ilanko $P$, Sirdaarta J, et al. Tasmannia stipitata as a functional food/natural preservative: Antimicrobial activity and toxicity. Pharmacognosy Communications. 2014;4(4):33-47. DOI: 10.5530/pc.2014.4.4

17. Mpala L, Chikowe G, Cock IE. No evidence of antiseptic properties and low toxicity of selected Aloe species. Journal of Pharmaceutical Negative Results. 2010;1(1):10-6. DOI: 10.4103/0976-9234.68869

18. Sirdaarda J, Matthews B, White A, et al. GC-MS and LC-MS analysis of Kakadu plum fruit extracts displaying inhibitory activity against microbial triggers of multiple sclerosis. Pharmacognosy Communications. 2015;5(2):100-15. DOI: 10.5530/pc.2015.2.2

19. Kalt FR, Cock IE. Gas chromatography-mass spectroscopy analysis of bioactive Petalostigma extracts: Toxicity, antibacterial and antiviral activities. Pharmacognosy Magazine. 2014;10(Suppl 1):S37-49. DOI: 10.4103/0973-1296.127338

20. Vesoul J, Cock IE. The potential of Bunya nut as an antibacterial food agent. Pharmacognosy Communications. 2012;2(1):72-9. DOI: 10.5530/pc.2012.1.13

21. Arkhipov A, Sirdaarta J, Rayan P, et al. An examination of the antibacterial, antifungal, anti-Giardial and anticancer properties of Kigelia africana fruit extracts. Pharmacognosy Communications. 2014;4(3):62-76. DOI: 10.5530/pc.2014.3.7

22. Cock IE. Antimicrobial activity of Acacia aulacocarpa and Acacia complanta methanolic extracts. Pharmacognosy Communications. 2012;2(1):66-71. DOI: 10.5530/pc.2012.1.12
23. Bryant K, Cock IE. Growth inhibitory properties of Backhousia myrtifolia Hook and Harv. and Syzygium anisatum (Vickery) Craven and Biffen extracts against a panel of pathogenic bacteria. Pharmacognosy Communications. 2016;6(4):194-203. DOI: $10.5530 / p c .2016 .4 .2$

24. Cock IE. Assessment of the toxicity of selected Australian native plant extracts using the Artemia franciscana nauplii bioassay. Internet Journal of Toxicology. 2008;5(2):2

25. Ruebhart DR, Wikramasinghe WA Cock IE. Protective efficacy of the antioxidants vitamin $\mathrm{E}$ and Trolox against Microcystis aeruginosa and microcystin-LR in Artemia franciscana nauplii. Journal of Toxicology and Environmental Health Part A. 2009;72(24):1567-75

26. Cock IE, Ruebhart DR. Comparison of the brine shrimp nauplii bioassay and the Tox Screen-II test for the detection of toxicity associated with Aloe vera (Aloe barbadensis Miller) leaf extract. Pharmacognosy Research. 2009;1(2):98-101.

27. Rashid T, Ebringer A. Autoimmunity in rheumatic diseases is induced by microbial infections via cross reactivity or molecular mimicry. Autoimmune Diseases. 2012.

28. Ebringer A, Rashid T, Wilson $\mathrm{C}$. The role of Acinetobacter in the pathogenesis of multiple sclerosis examined by using Popper sequences. Medical Hypotheses. 2012;78(6):763-9.

29. Ebringer $A$, Hughes $L$, Rashid T, et al. Acinetobacter immune response in multiple sclerosis. Etiopathogenetic role and its possible use as a diagnostic marker JAMA Neurology. 2005;62(1):33-6.

30. Rashid T, Ebringer A. Rheumatoid arthritis is caused by asymptomatic Proteus urinary tract infections. In: Nikibakhsh $A$ (ed) Clinical management of complicated urinary tract infection. In Tech. 2011;11.

31. Poole K. Efflux-mediated multiresistance in Gram-negative bacteria. Clinical Microbiology and Infection. 2004;10(1):12-26. DOI:10.1111/j.1469-0691.2004.00763.x

32. Cock IE. The phytochemistry and chemotherapeutic potential of Tasmannia lanceolata (Tasmanina pepper): a review. Pharmacognosy Communications. 2013;3(4):13-25. DOI: 10.5530/pc.2013.4.3

33. Cock IE. The medicinal properties and phytochemistry of plants of the genus Terminalia (Combretaceae). Inflammopharmacology. 2015:23(5):203-29. DOI 10.1007/s10787-015-0246-z

34. Buzzini P, Arapitsas P, Goretti M, et al. Antimicrobial activity of hydrolysable tannins. Mini-Reviews in Medicinal Chemistry. 2008:8(12):1179-87.

35. Hogg SD, Embery G. Blood-group-reactive glycoprotein from human saliva interacts with lipoteichoic acid on the surface of Streptococcus sanguis cells. Archives in Oral Biology. 1982;27(3):261-8.

36. Wu YCD, Chen CY, Wu RT. Gallotannins inhibit growth, water soluble glucan synthesis and aggregation of Streptococci mutans. Journal of Dental Research. $1988 ; 67(1): 51-5$
PICTORIAL ABSTRACT

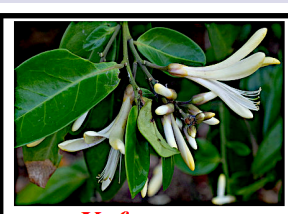

X. fragrans

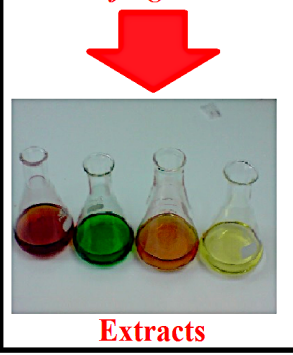

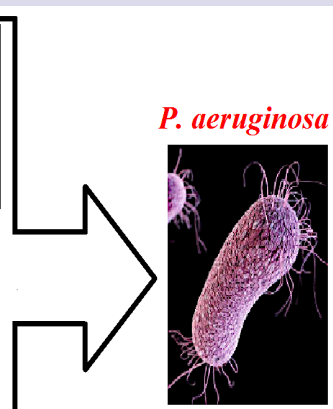

blocks bacterial growth

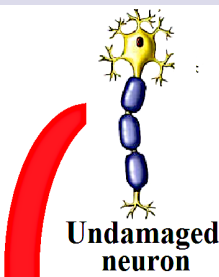

Blocks MS

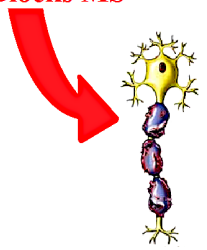

Damaged

myelin sheath

Dr lan Cock leads a research team in the Environmental Futures Research Institute and the School of Natural Sciences at Griffith University, Australia. His research involves bioactivity and phytochemical studies into a variety of plant species of both Australian and international origin, including Aloe vera, South Asian and South American tropical fruits, as well as Australia plants including Scaevola spinescens, Pittosporum phylliraeoides, Terminalia ferdinandiana (Kakadu plum), Australian Acacias, Syzygiums, Petalostigmas and Xanthorrhoea johnsonii (grass trees). This range of projects has resulted in nearly 200 publications in a variety of peer reviewed journals.

\section{SUMMARY}

- Xanthophyllum fragrans leaf extracts were tested for the ability to inhibit the growth of clinical and reference Pseudomonas aeruginosa strains.

- The inhibitory activity was quantified by MIC determination.

- Bacterial growth time course assay were used to further evaluate the nature of the growth inhibition.

- Toxicity was studied in the Artemia nauplii bioassay

\section{ABOUT AUTHORS}

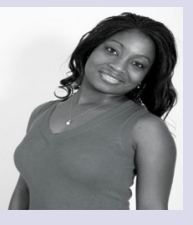

Ms Lindiwe Mpala completed at BSc at Griffith University in life sciences. Following graduation, she undertook a research project in Dr lan Cock's laboratory in the School of Natural Sciences at Griffith University. The project examined the growth inhibitory properties of a variety of Australian native plants against an extensive panel of bacterial pathogens.

Ms Getmore Chikowe completed at BSc at Griffith University in life sciences. Following graduation, she undertook a research project in $\mathrm{Dr}$ lan Cock's laboratory in the School of Natural Sciences at Griffith University. The project examined the growth inhibitory properties of a variety of Australian native plants against an extensive panel of bacterial pathogens. 